\title{
A Comparative Study on Beam Divergence Angle and Wave Length Between Semiconductor Laser and Helium-Neon Laser
}

\author{
Senamaw Mequanent Zgeye \\ Department of Physics, Collage of Natural and Computational Science, Debre Markos University, Debre Markos, Ethiopia
}

Email address:

sinamwi@gmail.com

To cite this article:

Senamaw Mequanent Zgeye. A Comparative Study on Beam Divergence Angle and Wave Length Between Semiconductor Laser and Helium-Neon Laser. American Journal of Mechanical and Industrial Engineering. Vol. 4, No. 5, 2019, pp. 69-75.

doi: 10.11648/j.ajmie.20190405.11

Received: September 21, 2019; Accepted: October 30, 2019; Published: November 5, 2019

\begin{abstract}
In this experimental study, I have seen that a comparative study on semiconductor laser and Helium-Neon laser is presented using the experimental techniques and tried to compare the experimental value with that of the theoretical one. On this work the wave length and beam divergence angle of the two types of lasers up to ten number of trials in the three orders, starting from $20 \mathrm{~cm}$ to $200 \mathrm{~cm}$, with an interval of $20 \mathrm{~cm}$ for each order was measured and I found that in the first and second order in the two types of laser, the wave length and the divergence angle is greater for Helium-Neon laser than semiconductor laser, thus, from this it is possible to understand that semiconductor laser is highly directional, means that it has high intensity, whereas, in the third order the Helium-Neon laser is not visible but semiconductor laser is visible, which is one of the indicator of Helium-Neon laser is not highly directional. And again, I examine that the beam divergence angle and wave length can have inverse relationship for the two types of lasers, as we see from figures 3 and 4. Thus, we concluded that the experimental result is almost agreed with that of the theoretical one.
\end{abstract}

Keywords: Directionality, Divergence Angle, Wavelength

\section{Introduction}

The term laser is an acronym for light amplification by stimulated emission of radiation. The laser was the first device capable of amplifying light waves themselves. The emitted laser light is a spatially coherent, narrow lowdivergence beam, when the waves (photons) of beam of light have the same frequency, phase and direction, it is said to be coherent [1]. Laser light is the study of emitting coherent electromagnetic radiation and they have assumed tremendous importance in the fields of science and technology because of their impact in both basic researches as well as in various technological applications [2]. They can be found consumer, goods and services such as music players, laser printers, scanners for product identification, industrial like that of metal cutting, welding, hole drilling, marking, medical surgery and applications of scientific research [3]. Laser light is available in all colors from red to violet and also far outside the conventional limits of the optical spectrum over wide portion of the available range laser light in different fields [4].

Laser light exactly the same color or monochromatic which means a single wave is occurred in laser light in one of the main characteristics of laser light is coherent, which described laser light different from light produced by any other sources of light wave produced by laser leave the larger traveling in very nearly the same direction [5]. One result of this directionality is that larger beam is focused to a very small spot, greatly increasing its intensity. The laser light is generally different characteristics such as coherence, directionality, monochromaticity, and high intensity [6].

When laser light is power full (high intensity) in a smallest wave length or in the largest frequency [7]. In fact that different wave length experience different propagation and therefore travels with different velocity casing a longer temporal pulse at the end of the fiber [8].

Laser can have various types among them in my study mainly; I am trying to focus on semiconductor laser and 
helium- neon laser. Semiconductor laser, which is electrically pumped laser. It is unique when compared to other types of laser [9]. They are very small; they operate in a different way in that they require the merging of two different materials and the laser action occurs in the interference between those two materials. One of the materials has an excess of electron (n-type) and the other material (p-type) has a deficit of electron [10, 11]. A semiconductor laser is used in the field of long distance communication and in compact disk players. Other uses of semiconductor laser includes high speed printing free space communication, pump sources for other solid state lasers (including fiber amplifiers), laser pointers, and various medical applications $[11,12]$. The semiconductor laser is highly directional than Helium-Neon laser, because it is highly convergent laser $[12,13]$.

Helium-Neon laser was one of the first lasers ever developed and is still one of the most widely used lasers. The lasers are trouble free and have extremely long operating lifetimes. They operate in low-pressure mixture of helium and neon gases, and the laser transitions occur within the neutral atomic species. The most common wave length is $632.8 \mathrm{~nm}$ transition in the red position of the spectrum $[13,14]$. Thus, we know that laser can have wide verities of applications and types, in this study mainly, I am trying to focus on the two types of lasers and say something about their beam divergence angle versus wave length and identifies, which laser types is highly directional, because according to the theoretical explanation the semiconductor laser is highly directional than Helium-Neon laser, now I was tried to verify this by experiment.

\section{The Objectives of This Study Are}

\subsection{General Objective}

The general objective of this research work is to study about the beam divergence angle and wave length between semiconductor laser and Helium-Neon laser.

\subsection{Specific Objective}

The specific objectives of this research work are:

1. To determine the beam divergence angle of semiconductor laser and Helium-Neon laser.

2. To determine the wave length of semiconductor laser and Helium-Neon laser.

3. To explain the relationship between wave length and divergence angle for the two types of laser.

4. To identify which laser type is highly directional.

\section{Materials and Methods}

\subsection{Study Area}

The University is found at Debre Markos town which is located in north western part of Ethiopia. The town is 300 Km's North West of the capital, Addis Ababa and 265 Km's south east of Bahir Dar, the capital of Amhara National Regional State. It is geographically located at $10^{\circ} 20^{\prime} \mathrm{N} 37^{\circ} 43^{\prime} \mathrm{E} / 10.333^{\circ} \mathrm{N} 37.717^{\circ} \mathrm{E}$ with an average altitude of $2446 \mathrm{~m}$ above sea level. It has conducive weather condition with $1380 \mathrm{~mm}$ average annual rainfall and $18^{\circ} \mathrm{C}$ average annual temperature. According to the municipality's report, the town has over 123,000 residents of which 97 percent are Amhara and the remaining three percent are from Agaw, Oromo, Tigre and others nations. Although there are various religions (orthodox Christians, Muslims and Evangelical Christians), most of the dwellers are Orthodox Christian.

The University is found in the area endowed with potential resources, such as the Choke Mountains watershade which covers six different agro-ecology zones within $50 \mathrm{~km}$ radius with various bio-diversity and the source of many tributaries to the Nile, and Upper Blue Nile Gorge. Around the vicinity of the University, there are historic, renowned and ancient church schools: Dima Giorgis, Mertule-Mariam, Debre Work Mariam and Debre Elias, etc. These schools played significant role in the development of modern education in Ethiopia. Prominent scholars who have contributed for the development of education and Ethiopian literature were the products of these traditional schools.

On the other hand, the university is found in the area with high environmental degradation such as soil erosion and degradation, deforestation, depletion of wet lands and reduction of water bodies. All these potentials and challenges are great opportunities for the university to effectively manage the teaching-learning, undertake research, and provide community service activities with wider applicability of the results. Thus, this research is mainly conducted in this university department of physics laboratory.

\subsection{Materials}

To conduct the experiment and collect the data the following instruments was used: grating (300lines $/ \mathrm{mm}$ ), helium-neon laser (red), semiconductor laser (green), screen, holder, ruler, and table.

\subsection{Data Collection}

To collect the data by using the above listed instruments, I have tried to setup the instruments as such given below: 


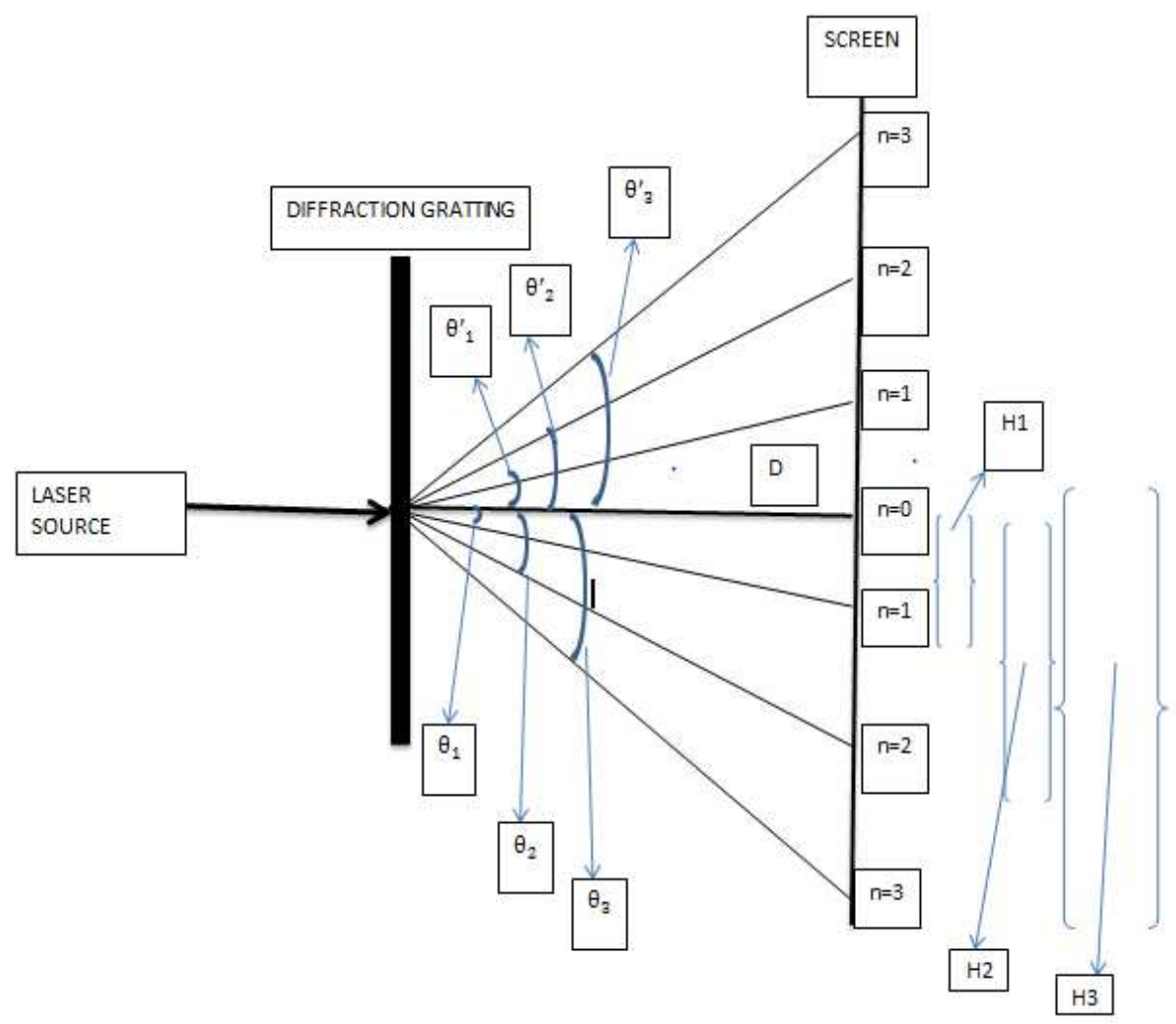

Figure 1. Experimental setup for theoretical calculations.

And again by using the correct experimental procedures one by one to their order the following data's were recorded. By using the following experimental setups shown in the figure below:

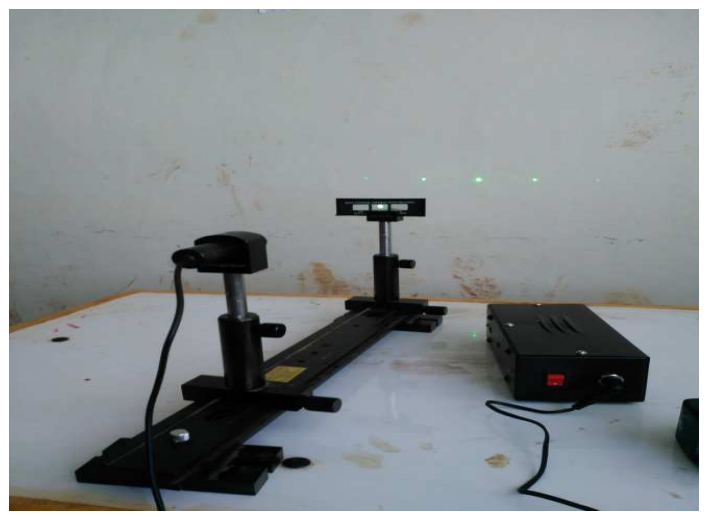

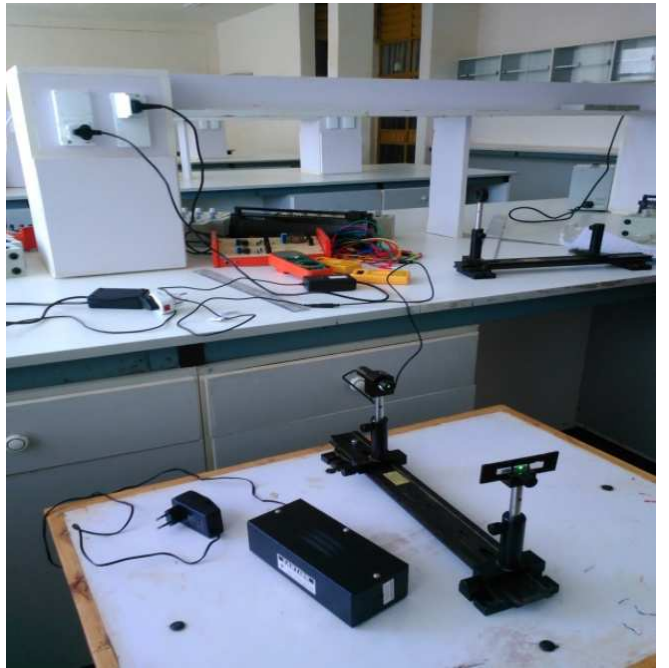

Figure 2. Experimental setup for experimental measurements.

Table 1. The laser source is semiconductor laser.

\begin{tabular}{|c|c|c|c|c|c|c|c|c|}
\hline \multirow{2}{*}{ Trial no. } & \multirow{2}{*}{ Order (m) } & \multirow{2}{*}{ D (cm) } & \multicolumn{3}{|c|}{$H_{n}(\mathrm{~cm})$} & \multirow{2}{*}{$\theta=\tan ^{-1}\left(\frac{H_{n}}{D}\right)$} & \multirow{2}{*}{$\sin \theta$} & \multirow{2}{*}{$\lambda(\boldsymbol{m})$} \\
\hline & & & LHS & RHS & Mean & & & \\
\hline 1 & 1 & 20 & 3.5 & 3.2 & 3.35 & & & \\
\hline 2 & 2 & 20 & 7 & 6.8 & 6.9 & & & \\
\hline 3 & 3 & 20 & 11.7 & 11.1 & 11.4 & & & \\
\hline 4 & 1 & 40 & 6.5 & 6.7 & 6.6 & & & \\
\hline 5 & 2 & 40 & 13.9 & 13.8 & 13.85 & & & \\
\hline 6 & 3 & 40 & 22.6 & 22.5 & 22.55 & & & \\
\hline 7 & 1 & 60 & 10 & 10 & 10 & & & \\
\hline 8 & 2 & 60 & 21.2 & 20.4 & 20.8 & & & \\
\hline 9 & 3 & 60 & 35 & 33 & 34 & & & \\
\hline 10 & 1 & 80 & 13.4 & 13.2 & 13.3 & & & \\
\hline 11 & 2 & 80 & 28 & 27.5 & 27.75 & & & \\
\hline 12 & 3 & 80 & 45 & 44.2 & 44.6 & & & \\
\hline
\end{tabular}




\begin{tabular}{|c|c|c|c|c|c|c|c|c|}
\hline \multirow{2}{*}{ Trial no. } & \multirow{2}{*}{ Order (m) } & \multirow{2}{*}{ D (cm) } & \multicolumn{3}{|c|}{$\mathrm{H}_{n}(\mathrm{~cm})$} & \multirow{2}{*}{$\theta=\tan ^{-1}\left(\frac{H_{n}}{D}\right)$} & \multirow{2}{*}{$\sin \theta$} & \multirow{2}{*}{$\lambda(\boldsymbol{m})$} \\
\hline & & & LHS & RHS & Mean & & & \\
\hline 13 & 1 & 100 & 16.6 & 16.5 & 16.55 & & & \\
\hline 14 & 2 & 100 & 34.6 & 34.4 & 34.5 & & & \\
\hline 15 & 3 & 100 & 55.9 & 55.8 & 55.85 & & & \\
\hline 16 & 1 & 120 & 19.9 & 19.9 & 19.9 & & & \\
\hline 17 & 2 & 120 & 41.4 & 41 & 41.2 & & & \\
\hline 18 & 3 & 120 & 67 & 66.8 & 66.9 & & & \\
\hline 19 & 1 & 140 & 23 & 23 & 23 & & & \\
\hline 20 & 2 & 140 & 47.5 & 47.5 & 47.5 & & & \\
\hline 21 & 3 & 140 & 76.1 & 79 & 77.55 & & & \\
\hline 22 & 1 & 160 & 26.2 & 26.6 & 26.4 & & & \\
\hline 23 & 2 & 160 & 54 & 56.2 & 55.1 & & & \\
\hline 24 & 3 & 160 & 86.4 & 92.5 & 89.45 & & & \\
\hline 25 & 1 & 180 & 29.2 & 29.8 & 29.5 & & & \\
\hline 26 & 2 & 180 & 60.9 & 62.5 & 61.7 & & & \\
\hline 27 & 3 & 180 & 97.7 & 102.8 & 100.25 & & & \\
\hline 28 & 1 & 200 & 33.3 & 33 & 33.15 & & & \\
\hline 29 & 2 & 200 & 69.5 & 68.5 & 69 & & & \\
\hline 30 & 3 & 200 & 113 & 111 & 112 & & & \\
\hline
\end{tabular}

Table 2. The laser source is Helium-Neon laser.

\begin{tabular}{|c|c|c|c|c|c|c|c|c|}
\hline \multirow{2}{*}{ Trial no. } & \multirow{2}{*}{ Order (m) } & \multirow{2}{*}{ D (cm) } & \multicolumn{3}{|c|}{$H_{n}(\mathrm{~cm})$} & \multirow{2}{*}{$\theta=\tan ^{-1}\left(\frac{H_{n}}{D}\right)$} & \multirow{2}{*}{$\sin \theta$} & \multirow{2}{*}{$\lambda(\boldsymbol{m})$} \\
\hline & & & LHS & RHS & Mean & & & \\
\hline 1 & 1 & 20 & 4.3 & 4.2 & 4.25 & & & \\
\hline 2 & 2 & 20 & 9.3 & 8.5 & 8.9 & & & \\
\hline 3 & 3 & 20 & ------ & ------ & ------- & & & \\
\hline 4 & 1 & 40 & 8.4 & 8 & 8.2 & & & \\
\hline 5 & 2 & 40 & 18.3 & 16.4 & 17.35 & & & \\
\hline 6 & 3 & 40 & ----- & ------- & ------ & & & \\
\hline 7 & 1 & 60 & 12.5 & 11.7 & 12.1 & & & \\
\hline 8 & 2 & 60 & 28 & 23.7 & 25.85 & & & \\
\hline 9 & 3 & 60 & ------ & ------ & ------- & & & \\
\hline 10 & 1 & 80 & 16.4 & 15.5 & 15.95 & & & \\
\hline 11 & 2 & 80 & 35.8 & 32 & 33.9 & & & \\
\hline 12 & 3 & 80 & ----- & ------ & -------- & & & \\
\hline 13 & 1 & 100 & 20.7 & 19.6 & 20.15 & & & \\
\hline 14 & 2 & 100 & 46 & 39.6 & 42.8 & & & \\
\hline 15 & 3 & 100 & ----- & ----- & ------ & & & \\
\hline 16 & 1 & 120 & 24.5 & 23.3 & 23.9 & & & \\
\hline 17 & 2 & 120 & 54 & 47.7 & 50.85 & & & \\
\hline 18 & 3 & 120 & ----- & ----- & ------- & & & \\
\hline 19 & 1 & 140 & 29 & 27.4 & 28.2 & & & \\
\hline 20 & 2 & 140 & 64.8 & 55.3 & 60.05 & & & \\
\hline 21 & 3 & 140 & ----- & ------ & --------- & & & \\
\hline 22 & 1 & 160 & 32.2 & 32 & 32.1 & & & \\
\hline 23 & 2 & 160 & 69 & 66.6 & 67.8 & & & \\
\hline 24 & 3 & 160 & ----- & ------ & -------- & & & \\
\hline 25 & 1 & 180 & 36.4 & 35 & 35.7 & & & \\
\hline 26 & 2 & 180 & 78.5 & 72.5 & 75.5 & & & \\
\hline 27 & 3 & 180 & ------ & ------ & ------- & & & \\
\hline 28 & 1 & 200 & 42.5 & 38.8 & 40.65 & & & \\
\hline 29 & 2 & 200 & 96 & 78.3 & 87.15 & & & \\
\hline 30 & 3 & 200 & ----- & ----- & ------- & & & \\
\hline
\end{tabular}

And the rest parameters i.e. the beam divergence angle and the wave length for each order and each laser types can be calculated from the following formulas: [14]

To calculate the wave length:

$$
m \lambda=\operatorname{asin} \theta
$$

And also to find the beam divergence angle:

$$
\theta=\tan -1\left(H_{n} / D\right)
$$

$a$, is the number of lines per meter in the grating in lines $/ \mathrm{mm}$, which is called as the grating element and defined as the distance between two consecutive slits (lines) of grating.

$H_{n}$, is the distance of the spot from the central maximum in $\mathrm{m}$.

$D$, is the perpendicular distance between grating and the scale in $\mathrm{m}$.

$m$, is the order of the spectrum.

Again, after calculating the possible values, the result can be summarized as in the following table, for the two types of lasers: 
Table 3. The laser source is semiconductor laser.

\begin{tabular}{|c|c|c|c|c|c|c|c|c|}
\hline \multirow{2}{*}{ Trial no. } & \multirow{2}{*}{ Order (m) } & \multirow{2}{*}{ D (cm) } & \multicolumn{3}{|c|}{$H_{n}(\mathrm{~cm})$} & \multirow{2}{*}{$\theta=\tan ^{-1}\left(\frac{H_{n}}{D}\right)$ In degree } & \multirow{2}{*}{$\sin \theta$} & \multirow{2}{*}{$\lambda(\boldsymbol{m})$} \\
\hline & & & LHS & RHS & Mean & & & \\
\hline 1 & 1 & 20 & 3.5 & 3.2 & 3.35 & 9.50877 & 0.1652 & $5.51 \times 10^{-7}$ \\
\hline 2 & 2 & 20 & 7 & 6.8 & 6.9 & 19.034434 & 0.3262 & $5.43 \times 10^{-7}$ \\
\hline 3 & 3 & 20 & 11.7 & 11.1 & 11.4 & 29.68314 & 0.4952 & $5.50 \times 10^{-7}$ \\
\hline 4 & 1 & 40 & 6.5 & 6.7 & 6.6 & 9.369385 & 0.1628 & $5.43 \times 10^{-7}$ \\
\hline 5 & 2 & 40 & 13.9 & 13.8 & 13.85 & 19.098412 & 0.3272 & $5.45 \times 10^{-7}$ \\
\hline 6 & 3 & 40 & 22.6 & 22.5 & 22.55 & 29.41212997 & 0.4911 & $5.456 \times 10^{-7}$ \\
\hline 7 & 1 & 60 & 10 & 10 & 10 & 9.46232 & 0.1644 & $5.458 \times 10^{-7}$ \\
\hline 8 & 2 & 60 & 21.2 & 20.4 & 20.8 & 19.1197 & 0.3275 & $5.459 \times 10^{-7}$ \\
\hline 9 & 3 & 60 & 35 & 33 & 34 & 29.53878 & 0.4930 & $5.478 \times 10^{-7}$ \\
\hline 10 & 1 & 80 & 13.4 & 13.2 & 13.3 & 9.4391 & 0.1640 & $5.466 \times 10^{-7}$ \\
\hline 11 & 2 & 80 & 28 & 27.5 & 27.75 & 19.1304 & 0.3277 & $5.462 \times 10^{-7}$ \\
\hline 12 & 3 & 80 & 45 & 44.2 & 44.6 & 29.13966 & 0.48694 & $5.4104 \times 10^{-7}$ \\
\hline 13 & 1 & 100 & 16.6 & 16.5 & 16.55 & 9.3973 & 0.1633 & $5.443 \times 10^{-7}$ \\
\hline 14 & 2 & 100 & 34.6 & 34.4 & 34.5 & 19.03443 & 0.3261 & $5.4356 \times 10^{-7}$ \\
\hline 15 & 3 & 100 & 55.9 & 55.8 & 55.85 & 29.1834 & 0.4876 & $5.4178 \times 10^{-7}$ \\
\hline 16 & 1 & 120 & 19.9 & 19.9 & 19.9 & 9.415859 & 0.1636 & $5.453 \times 10^{-7}$ \\
\hline 17 & 2 & 120 & 41.4 & 41 & 41.2 & 18.949 & 0.3247 & $5.4121 \times 10^{-7}$ \\
\hline 18 & 3 & 120 & 67 & 66.8 & 66.9 & 29.1396 & 0.4869 & $5.4104 \times 10^{-7}$ \\
\hline 19 & 1 & 140 & 23 & 23 & 23 & 9.3295 & 0.1621 & $5.4038 \times 10^{-7}$ \\
\hline 20 & 2 & 140 & 47.5 & 47.5 & 47.5 & 18.7413 & 0.3213 & $5.3549 \times 10^{-7}$ \\
\hline 21 & 3 & 140 & 76.1 & 79 & 77.55 & 28.9833 & 0.4845 & $5.3839 \times 10^{-7}$ \\
\hline 22 & 1 & 160 & 26.2 & 26.6 & 26.4 & 9.3693 & 0.16279 & $5.4266 \times 10^{-7}$ \\
\hline 23 & 2 & 160 & 54 & 56.2 & 55.1 & 19.0024 & 0.3256 & $5.4268 \times 10^{-7}$ \\
\hline 24 & 3 & 160 & 86.4 & 92.5 & 89.45 & 29.2079 & 0.48798 & $5.422 \times 10^{-7}$ \\
\hline 25 & 1 & 180 & 29.2 & 29.8 & 29.5 & 9.30739 & 0.161731 & $5.391 \times 10^{-7}$ \\
\hline 26 & 2 & 180 & 60.9 & 62.5 & 61.7 & 18.92057 & 0.292847 & $4.8808 \times 10^{-7}$ \\
\hline 27 & 3 & 180 & 97.7 & 102.8 & 100.25 & 32.35042 & 0.486569 & $5.4063 \times 10^{-7}$ \\
\hline 28 & 1 & 200 & 33.3 & 33 & 33.15 & 10.4569 & 0.163519 & $5.4506 \times 10^{-7}$ \\
\hline 29 & 2 & 200 & 69.5 & 68.5 & 69 & 21.14937 & 0.3261 & $5.4356 \times 10^{-7}$ \\
\hline 30 & 3 & 200 & 113 & 111 & 112 & 32.498695 & 0.4886 & $5.4289 \times 10^{-7}$ \\
\hline
\end{tabular}

Table 4. The laser source is Helium-Neon laser.

\begin{tabular}{|c|c|c|c|c|c|c|c|c|}
\hline \multirow{2}{*}{ Trial no. } & \multirow{2}{*}{ Order (m) } & \multirow{2}{*}{ D (cm) } & \multicolumn{3}{|c|}{$H_{n}(\mathrm{~cm})$} & \multirow{2}{*}{$\theta=\tan ^{-1}\left(\frac{H_{n}}{D}\right)$ In degree } & \multirow{2}{*}{$\sin \theta$} & \multirow{2}{*}{$\lambda(\boldsymbol{m})$} \\
\hline & & & LHS & RHS & Mean & & & \\
\hline 1 & 1 & 20 & 4.3 & 4.2 & 4.25 & 13.32988 & 0.207858 & $6.9286 \times 10^{-7}$ \\
\hline 2 & 2 & 20 & 9.3 & 8.5 & 8.9 & 26.6545 & 0.406562 & $6.776 \times 10^{-7}$ \\
\hline 4 & 1 & 40 & 8.4 & 8 & 8.2 & 12.87236 & 0.2008 & $6.6941 \times 10^{-7}$ \\
\hline 5 & 2 & 40 & 18.3 & 16.4 & 17.35 & 26.0542 & 0.39793 & $6.6322 \times 10^{-7}$ \\
\hline 6 & 3 & 40 & ----- & ------ & -------- & ------ & ----- & ----- = \\
\hline 7 & 1 & 60 & 12.5 & 11.7 & 12.1 & 12.668581 & 0.19768 & $6.5896 \times 10^{-7}$ \\
\hline 8 & 2 & 60 & 28 & 23.7 & 25.85 & 25.897764 & 0.39567 & $6.5946 \times 10^{-7}$ \\
\hline 9 & 3 & 60 & ------ & ----- & ------- & ----- & ------ & -------- \\
\hline 10 & 1 & 80 & 16.4 & 15.5 & 15.95 & 11.275495 & 0.1955 & $6.5176 \times 10^{-7}$ \\
\hline 11 & 2 & 80 & 35.8 & 32 & 33.9 & 22.9648 & 0.39016 & $6.5028 \times 10^{-7}$ \\
\hline 12 & 3 & 80 & ----- & ------ & -------- & ------ & ----- & ------- \\
\hline 13 & 1 & 100 & 20.7 & 19.6 & 20.15 & 11.392546 & 0.197529 & $6.5843 \times 10^{-7}$ \\
\hline 14 & 2 & 100 & 46 & 39.6 & 42.8 & 23.171 & 0.39348 & $6.5579 \times 10^{-7}$ \\
\hline 15 & 3 & 100 & ----- & ---- & ------ & ----- & ------- & -------- \\
\hline 16 & 1 & 120 & 24.5 & 23.3 & 23.9 & 11.2640 & 0.19533 & $6.511 \times 10^{-7}$ \\
\hline 18 & 3 & 120 & ----- & ----- & ------- & ----- & ------- & ------- \\
\hline 19 & 1 & 140 & 29 & 27.4 & 28.2 & 11.3886 & 0.19746 & $6.5821 \times 10^{-7}$ \\
\hline 20 & 2 & 140 & 64.8 & 55.3 & 60.05 & 23.255875 & 0.3942 & $6.5699 \times 10^{-7}$ \\
\hline 21 & 3 & 140 & ----- & ------ & --------- & ----- & ----- & ----- ～～～ \\
\hline 22 & 1 & 160 & 32.2 & 32 & 32.1 & 11.34436 & 0.19671 & $6.5568 \times 10^{-7}$ \\
\hline 23 & 2 & 160 & 69 & 66.6 & 67.8 & 22.9648 & 0.3902 & $6.5028 \times 10^{-7}$ \\
\hline 24 & 3 & 160 & ----- & ------ & -------- & ------ & -------- & ------- \\
\hline 25 & 1 & 180 & 36.4 & 35 & 35.7 & 11.2181 & 0.194544 & $6.4848 \times 10^{-7}$ \\
\hline 26 & 2 & 180 & 78.5 & 72.5 & 75.5 & 22.75534 & 0.386796 & $6.4466 \times 10^{-7}$ \\
\hline 27 & 3 & 180 & ------ & ----- & ------- & ------ & ------- & -------- \\
\hline 28 & 1 & 200 & 42.5 & 38.8 & 40.65 & 11.4888 & 0.199176 & $6.6392 \times 10^{-7}$ \\
\hline 29 & 2 & 200 & 96 & 78.3 & 87.15 & 23.5452 & 0.3995 & $6.6579 \times 10^{-7}$ \\
\hline 30 & 3 & 200 & ----- & ----- & ------- & ------- & ------ & ------ \\
\hline
\end{tabular}

Based on the above given table 1 and table 2 we have the following wave length vs. beam divergence angle for semiconductor laser and $\mathrm{He}-\mathrm{Ne}$ laser, for figure 3 and figure 4 given below, respectively: 


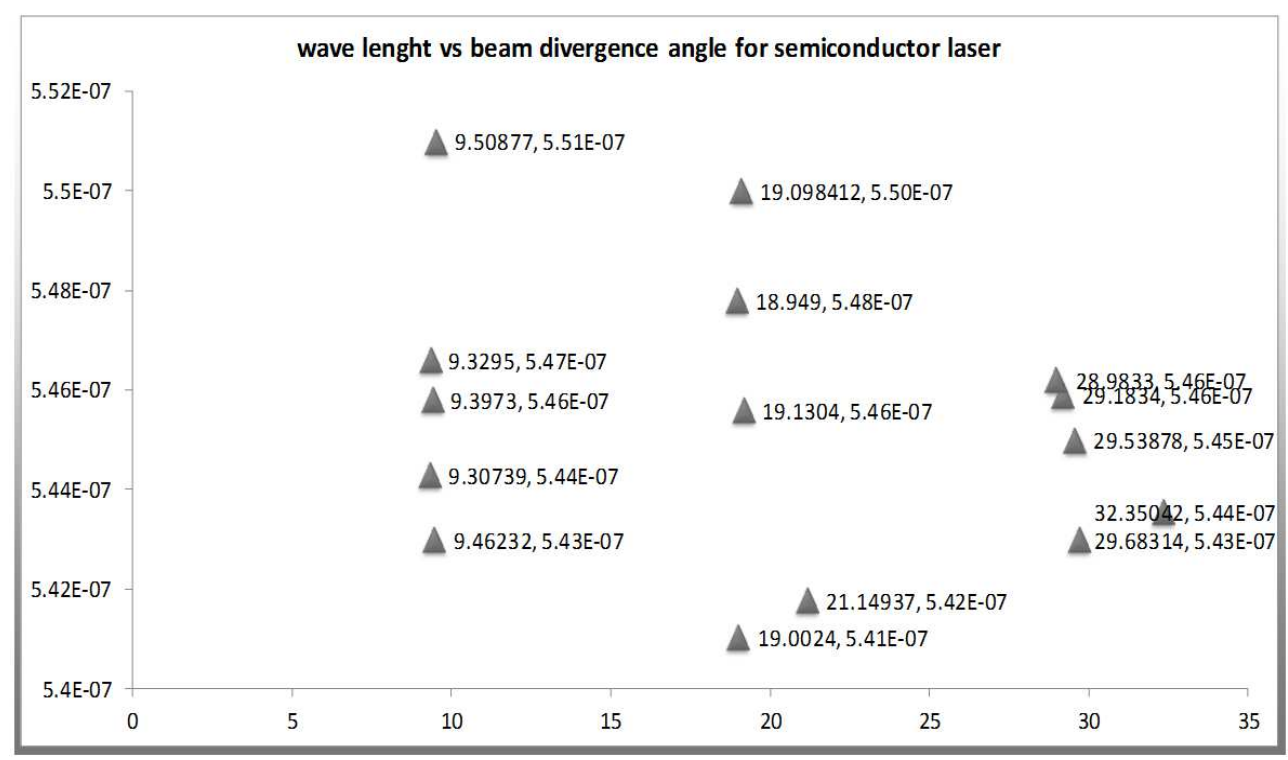

Figure 3. Wave length vs. beam divergence angle for semiconductor laser.

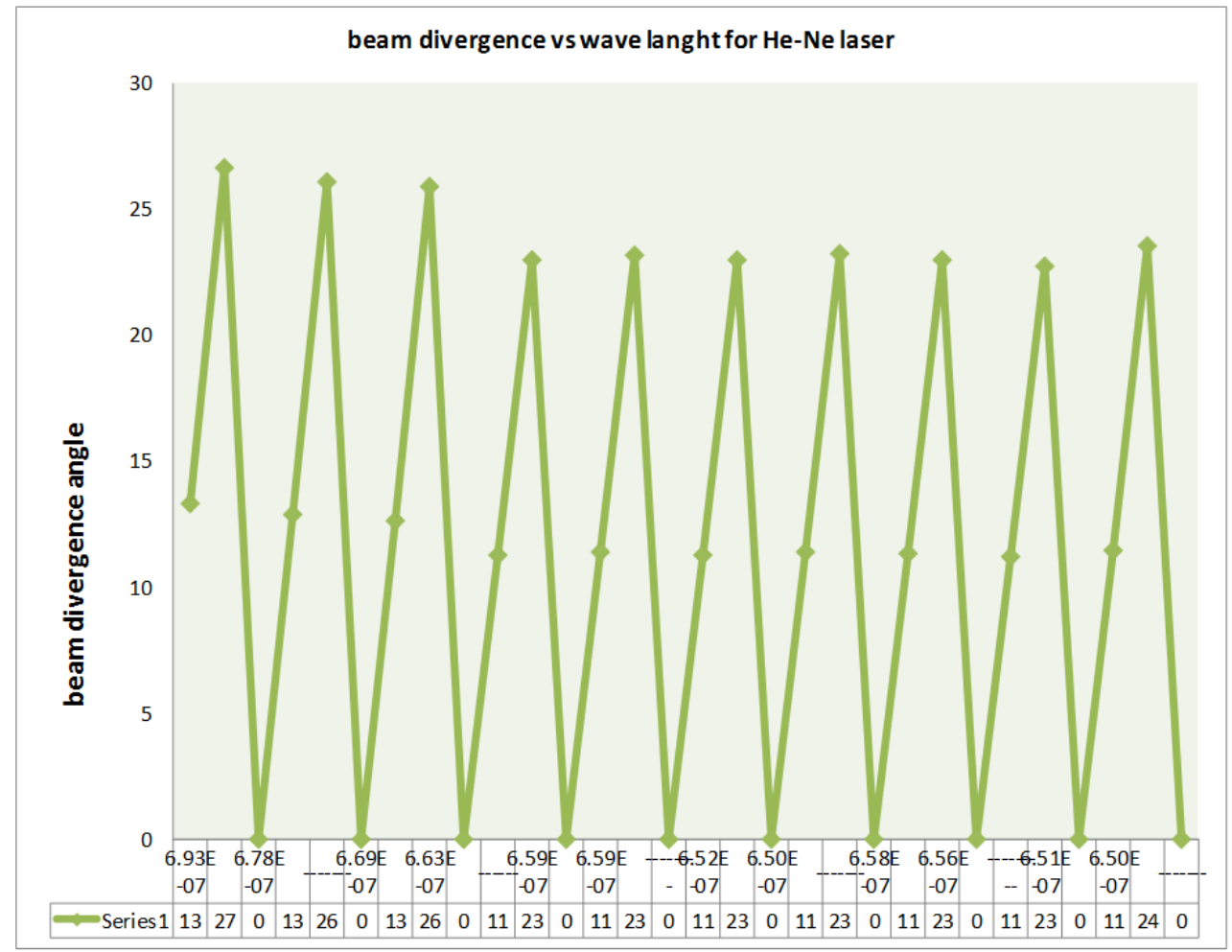

Figure 4. Wave length vs. beam divergence angle for He-Ne laser.

\section{Result and Discussion}

As we see from the above tables 1 and 2 and figures 3 and 4 we examine that the relationship between beam divergence angle and wave length for each order and each number of trials, in the first order and second order measurement starting from trial one up to the last trial, the Helium-Neon laser can have high beam divergence angle and also wave length, but semiconductor laser can have low beam divergence angle and wave length but in the third order trial Helium-Neon laser is not visible, whereas, semiconductor laser is visible, thus, from this result we examine that the semiconductor laser has highly directional than Helium-Neon laser. And also, for the two types of laser the beam divergence angle and wave length can have inverse relations.

\section{Conclusion}

In this work, I have presented an experimental analysis of the two types of laser of their wave length and beam divergence angle for ten numbers of trials. Thus, from this study the result indicates that for the two types of laser the 
phenomenon of beam divergence angel and wave length can be calculated but for Helium-Neon laser in the third order calculation is not possible, which is not visible. And also, I have seen in both types of laser up to second order, the wave length and beam divergence angle can have inverse relations and we can say that, since, semiconductor laser is electrically pumped it is highly directional and intense than HeliumNeon laser. Thus, I concluded that the experimental result is almost agreed with the theoretical one.

\section{Recommendation}

After doing the research, the researcher can forward the following points as recommendation for the future researcher. If anyone, who is interested to do further study on this topic and related topics, a number of trials and orders should be greater than what I used in this study.

\section{Acknowledgements}

First and for the most, I would like to thank the almighty God for giving me strength to do this research paper. Secondly, my deepest and whole gratitude goes to my family specially my beloved child Yonatan Senamaw with his Mother Kelebie Tamiru for their moral and financial support, encouragement and advice throughout my education and my study at large.

\section{References}

[1] Peter W. Milonni and Joseph H. Ebrli, laser physics, Wiley and son Inc, (2009).

[2] Murrav III Sargent, Maraln O. Scully and Willis E. Lamb, laser physics, west view press, (1978).
[3] O. Svel to and Dc Hanna, principle of lasers, springs, 5th edition, (2010).

[4] F. A. Whites, fundamentals of optics, MCG raw Hill, 4th edition, (2001).

[5] Shich C. L; D. E. E. Ackley, and H. C. Lee, temperature insensitive vertical cavity surface emitting laser, V. S patent NO. 5274,655, (1993).

[6] Andeson, SG, Annual review of laser markets, lasr focus world 32: 50, (1996).

[7] T. Maiman, stimulated optical radiation in ruby, nature vol. 1187, 47736, pp. 493-494, (1960).

[8] R. F. Kazarinov and R. A. Suris, Fiz. Tekh, Poluprovedn, Original concept and theoretical prediction, 5, pp. 797-800, (1971).

[9] J. Gowar, optical communication systems, prentice Hall, London, (1984).

[10] B. Mroziewiez, External cavity wave length tunable semiconductor lasers-a review, opt-Electron, Rov. 16, no. 4, (2008).

[11] Elie Kapon, semiconductor laser I fundamentals/optics and photonics press/, Santiago London Boston, New York Sydney Tokyo Toronto, vol. 2, (1999).

[12] M. I. Nathan, semiconductor lasers, Appl. opt. 5, 1514-1528, (1966).

[13] K. D. Mielenz, K. F. Nefflen, W. R. C. Rowley, D. C. Wilson, and E. England, reproducibility of helium-neon laser wavelengths at $633 \mathrm{~nm}$, vol. 7 , no. $2,(1968)$.

[14] Lau, K. Y.; Yariv, A., Ultra high speed semiconductor lasers, IEEE Journal of Quantum Electronics, volume. 21, issue. 2, pp. 121-138, (1985). 